ORIGINAL ARTICLE

\title{
Parent reported home smoking bans and toddler (18-30 month) smoke exposure: a cross-sectional survey
}

\author{
N Spencer, C Blackburn, S Bonas, C Coe, A Dolan
}

Arch Dis Child 2005;90:670-674. doi: 10.1136/adc.2004.054684

See end of article for authors' affiliations

.....................

Correspondence to: Professor N Spencer School of Health and Social Studies, University of Warwick, Coventry CV4 7AL, UK; n.j.spencer@ warwick.ac.uk

Accepted

17 November 2004

\begin{abstract}
Aims: To study the relation between the use of parent reported home smoking bans and smoke exposure among children aged 18-30 months.

Methods: A total of 309 smoking households with children aged 18-30 months, who were part of the Coventry Cohort study, consented to participate in this cross-sectional survey.

Results: Although parents in almost $88 \%$ of smoking households reported using harm reduction strategies to protect their toddlers from smoke exposure, only $13.9 \%$ reported smoking bans in the house. Mean log urinary cotinine:creatinine ratio was significantly lower for those children whose parents reported no smoking in the house $(1.11,95 \% \mathrm{Cl} 0.64$ to 1.49$)$ compared with none/less strict strategies $(1.87,95 \% \mathrm{Cl}$ 1.64 to 2.10$)$. In linear regression models fitted on log cotinine:creatinine ratio, no smoking in the house was independently associated with a significant reduction in cotinine:creatinine ratio $(B=-0.55,95 \% \mathrm{Cl}$ -0.89 to -0.20 ) after adjusting for mother's and partner's average daily cigarette consumption, housing tenure, and overcrowding. The final model accounted for $44.3 \%$ of the variance.

Conclusions: Not smoking in the house was associated with a reduction in mean urinary cotinine:creatinine ratio in children aged 18-30 months; the relation persisted after adjustment for levels of mother's and partner's daily cigarette consumption and sociodemographic factors. Results suggest that home smoking bans in this age group have a small but significant effect on smoke exposure independent of levels of parental tobacco consumption.
\end{abstract}

$\mathrm{P}$ assive inhalation by young children of environmental tobacco smoke (ETS) is associated with an increased risk of a range of adverse outcomes. ${ }^{1-3}$ The WHO report estimates that globally 700 million children, half the world's children, breathe air polluted by tobacco smoke and that ETS is causally related to increased risks of respiratory infections in the first years of life, chronic respiratory illness in school aged children, middle ear disease, and sudden infant death. ETS has also been associated with learning difficulties, behaviour problems, and language difficulties in childhood although further work is needed to clarify whether these associations are causal or related to the social patterning of smoking. ${ }^{3}$ In addition to the health impact, the economic burden is considerable: the estimated annual cost of ETS in the first year of life in Hong Kong was over 2.1 million US dollars. ${ }^{4}$

Smoking cessation by parents of young children might be expected to reduce these risks but parental smoking habits during and after pregnancy appear resistant to health education messages to stop smoking. ${ }^{5}$ An alternative approach might be to encourage parents and other household members who feel unable to stop smoking in the short term to change their smoking habits by avoiding smoking in the presence of their children. Observational studies of smoking bans within the home suggest that these may be effective in reducing children's exposure to ETS. In a previous paper on the effects of harm reduction strategies on smoke exposure in households with infants aged 2-3 months, we reported a small but significant reduction in infant urinary cotinine: creatinine ratio associated with a ban on smoking within the home independent of adult tobacco consumption levels. ${ }^{6}$ Other studies report significant reductions in objective measures of ETS exposure associated with harm reduction strategies within the family home. ${ }^{7-11}$ Two studies report significant reduction in urinary cotinine levels associated with harm reduction strategies short of a total ban on smoking in the house. ${ }^{78}$ The remaining three studies $^{9-11}$ conclude that a total ban on smoking in the home is associated with the greatest reduction of ETS exposure short of parental smoking cessation. One study using hair nicotine levels among children aged 3 months to 10 years failed to show any significant reduction associated with smoking outside the home. ${ }^{12}$

Randomised control trials of smoking control programmes to reduce children's ETS exposure have produced variable results. A Cochrane review, ${ }^{13}$ undertaken in October 2001 but including one trial published in early 2002, ${ }^{14}$ identified 18 trials of family and carer smoking control programmes for reducing children's ETS exposure. Fifteen trials ${ }^{14-28}$ reported interventions aimed at reducing children's ETS exposure within the home. Only four trials ${ }^{16} 182026$ showed an intervention effect and the authors conclude that there is limited support for more intensive counselling interventions but none for brief interventions. ${ }^{13}$ Gehrman and Hovell, ${ }^{29}$ based on a critical review of 19 empirical studies published between 1987 and 2002, conclude that interventions of greater intensity and duration and those based on sound behaviour change theory yielded the most promising results.

Only four of the randomised controlled trials (RCTs) ${ }^{14} 172123$ included in the Cochrane review ${ }^{13}$ report the effect of interventions designed specifically to encourage a ban on smoking in the home. None of these reported an intervention effect; however, in three ${ }^{14} 1723$ there was no significant difference between intervention and control groups on the achievement of a smoking ban. The remaining study $^{21}$ reports no information comparing intervention and control groups for home smoking bans. The interventions in five further trials ${ }^{1820222627}$ involved the negotiation of options for reducing children's tobacco smoke exposure in the home but carers could choose their preferred option. In one trial, smoking outside the home is listed as the least favoured option. ${ }^{18}$ Published trials, therefore, currently 
provide little evidence about the effectiveness of smoking bans in the home in the reduction of children's tobacco smoke exposure.

In order to confirm that the effects of parent reported home smoking bans on smoke exposure among young mobile children were similar to those noted for infants, ${ }^{6}$ we undertook a community based survey of children aged 1830 months in smoking households. We tested the hypothesis that, independent of household cigarette consumption, socioeconomic status and overcrowding, not smoking in the home is associated with a statistically significant reduction in smoke exposure measured by cotinine in children's urine.

\section{METHODS}

Main carers (referred to as mothers in the remainder of the paper as $>95 \%$ were mothers) of children living in smoking households who had previously been enrolled as members of the Coventry Cohort, ${ }^{30}$ a whole year birth cohort study, were invited by letter and telephone to participate in the study. Mothers, giving informed consent, were interviewed in their homes when the child was 18-30 months old. Data related to use of home smoking bans and other harm reduction strategies, household cigarette consumption, and sociodemographic and home environment data were collected using a previously piloted structured interview schedule. Urine was collected from the child for urinary cotinine:creatinine ratio estimation at the time of the interview. Ethical approval was obtained from Coventry Research Ethics Committees.

Table 1 Sociodemographic characteristics of smoking households in the study

\begin{tabular}{lc}
\hline $\begin{array}{l}\text { Sociodemographic characteristics of smoking } \\
\text { households }\end{array}$ & No. (\%) \\
\hline Household income/year & $105(34.0 \%)$ \\
$<£ 10,000$ & $149(48.2 \%)$ \\
$£ 10,000-30,000$ & $40(12.9 \%)$ \\
£30,000+ & $15(4.9 \%)$ \\
Missing & \\
Overcrowding (excl. kitchen, bathroom, toilet) & $198(64.1 \%)$ \\
$\leqslant 1$ room/person & $101(32.7 \%)$ \\
>1 room/person & $10(3.2 \%)$ \\
Missing & \\
Mother's educational level & $88(28.5 \%)$ \\
High (A level or above) & $163(52.8 \%)$ \\
Medium (GCSE/O level) & $58(18.8 \%)$ \\
Low (no qualifications/GCSE ungraded) & 0 \\
Missing & \\
Receipt of state benefits & $120(38.8 \%)$ \\
Yes & $187(60.5 \%)$ \\
No & $2(0.7 \%)$ \\
Missing & \\
Housing tenure & $179(57.9 \%)$ \\
Owner occupier & $128(41.4 \%)$ \\
Rented & $2(0.6 \%)$ \\
Other & \\
Marital status & $256(82.8 \%)$ \\
Married/cohabiting & $53(17.2 \%)$ \\
Single parent & 0 \\
Missing & \\
Ethnicity & $293(94.8 \%)$ \\
White European & $11(3.6 \%)$ \\
Asian & $1(0.3 \%)$ \\
Black & $4(.3 \%)$ \\
Mixed/other & 0 \\
Missing & \\
\hline & \\
& \\
\hline &
\end{tabular}

\section{Exposure variables}

To address the main research question, reported use of home smoking bans and other harm reduction strategies was initially trichotomised as follows: home smoking ban; smoking permitted in the house but restrictions placed on smoking in the vicinity of the child and/or active steps taken to air room after smoking; none used and/or mother not aware of strategies that can reduce the child's smoke exposure. As children's mean cotinine:creatinine ratios were not significantly different in the restrictions short of a home smoking ban and none/not aware groups, the harm reduction variable was dichotomised to home smoking ban versus restrictions short of a smoking ban or none or not aware. Mother's average daily cigarette consumption (0; 1-9; 10-19; $20-29 ; 30-39 ; 40+)$, partner's average daily cigarette consumption $(0 ; 1-9 ; 10-19 ; 20-29 ; 30-39 ; 40+)$, housing tenure (rented $v$ owner occupied housing), and overcrowding $(\leqslant 1$ room per person $v>1$ room per person excluding kitchen, bathroom, and toilet) were extracted from the interview data as potential confounding variables.

\section{Outcome variable}

Children's smoke exposure was represented by the urinary cotinine:creatinine ratio. This was estimated using a competitive enzyme immunoassay (ELISA) method. The ratios were not normally distributed. Urinary cotinine:creatinine ratios were $\log$ transformed to attain normal distribution for entry into linear regression analysis.

\section{Analysis}

Mean log cotinine:creatinine ratio for parent reported use of a home smoking ban was compared with that for use of restrictions short of a home smoking ban/no measures (a range from not smoking in same room as child to none used). To control for confounding by mother's and partner's cigarette consumption, housing tenure, and overcrowding, multiple regression models were fitted on log cotinine: creatinine ratios. Model 1 regressed use of home smoking ban on log cotinine:creatinine ratio. Potential confounding variables were added sequentially, starting with mother's average daily cigarette consumption (model 2 ), followed by partner's average daily cigarette consumption (model 3), housing tenure (model 4), and finally overcrowding (model $5)$. The order of entry of independent variables into the regression models was based on their likely importance as confounding variables. Reversal of the order did not alter the additional variance attributed to confounding variables. All analyses were undertaken in SPSS version $10 .^{31}$

\section{RESULTS}

Table 1 presents the sociodemographic characteristics of the 309 smoking households enrolled in the study. Study households were less likely to have high qualifications, less likely to own their homes, more likely to be single, and less likely to be from a black or ethnic minority group than all families enrolled in the Coventry Cohort Study. ${ }^{30}$ However, smoking households that had enrolled in the Coventry Cohort Study but refused to participate in the present study had similar levels of single parent and ethnic minority households, but were less educated and less likely to own their own homes than the households participating in the present study. Missing data resulted in different numbers of households entered into the regression models (see table 3 ).

Table 2 outlines the harm reduction measures parents reported using. Only a small proportion (12.2\%) reported not using or not knowing of any measures to protect their child from exposure to environmental tobacco smoke, with over half reporting using more than one measure. Only $14 \%$ 
Table 2 Use of measures by parents from 309 smoking households to reduce their child's exposure to environmental tobacco smoke at home

\begin{tabular}{|c|c|}
\hline Details of measure & $\%(n)$ \\
\hline \multicolumn{2}{|l|}{ Number of measures used } \\
\hline None & $12.2(38)$ \\
\hline 1 & $25.6(79)$ \\
\hline 2 & $19.1(59)$ \\
\hline 3 or more & $42.0(130)$ \\
\hline \multicolumn{2}{|l|}{ Measures used } \\
\hline Do not smoke, or allow smoking, in the house & $13.9(43)$ \\
\hline Stopped smoking & $1.0(3)$ \\
\hline Smoke fewer cigarettes & $6.8(21)$ \\
\hline Do not smoke, or allow smoking, in same room as child & $23.3(72)$ \\
\hline Do not smoke, or allow smoking, in the living room & $9.4(29)$ \\
\hline $\begin{array}{l}\text { Do not smoke, or allow smoking, where child sleeps or } \\
\text { naps }\end{array}$ & $27.5(85)$ \\
\hline Air room when smoking or someone else smoking & $47.6(147)$ \\
\hline $\begin{array}{l}\text { Air room after smoking or after someone else has } \\
\text { smoked }\end{array}$ & $45.0(139)$ \\
\hline Other* & $48.5(150)$ \\
\hline \multicolumn{2}{|l|}{ Severity of measures used } \\
\hline Strict & $13.9(43)$ \\
\hline Less strict & $73.5(223)$ \\
\hline None or not aware of any & $12.2(38)$ \\
\hline \multicolumn{2}{|c|}{$\begin{array}{l}\text { Sum of percentages may exceed } 100 \% \text { as carers reported using more } \\
\text { than one measure. } \\
\text { *Includes: washing hands after smoking, using ioniser, using ceiling fan, } \\
\text { use of air freshener, not allowing smoker to cuddle child during or after } \\
\text { smoking. }\end{array}$} \\
\hline
\end{tabular}

reported using the strictest measure: not smoking or allowing smoking in the house.

The mean log cotinine:creatinine ratio for children in households operating a smoking ban was 1.11 (95\% CI 0.64 to 1.49 ) and was significantly lower than that for restrictions short of a total ban 1.87 (95\% CI 1.64 to 2.16). In linear regression models fitted on log cotinine:creatinine ratio, strict harm reduction alone was associated with a significant reduction in cotinine:creatinine ratio $(\mathrm{B}=-0.76$; 95\% CI -1.17 to -0.35 ) accounting for $7.1 \%$ of the variance (see model 1 , table 3 ). The independent association with a significant reduction in infant cotinine:creatinine remained, although the regression coefficient was reduced $(B=-0.55$; $95 \%$ CI -0.89 to -0.20$)$, after adjustment for mother's and partner's average daily cigarette consumption, housing tenure, and overcrowding (models $2-5$, table 3 ). Inclusion of mother's average consumption in the model (see model 2, table 3) accounted for a third of the effect of strict harm reduction ( $\mathrm{B}$ reduced to -0.55 from -0.76 ) on cotinine: creatinine ratio and accounted for an additional $28.7 \%$ of the variance $\left(\mathrm{R}^{2}\right.$ increase from $7.1 \%$ in model 1 to $35.8 \%$ in model 2 , table 2). Partner's average daily cigarette consumption had a small but significant independent effect on children's smoke exposure in the final model $(\mathrm{B}=0.17 ; 95 \%$ CI 0.05 to 0.30 ); however, adding it to the model only explained an additional $0.8 \%$ of the variance (see model 3, table 3 ). Housing tenure as a marker of socioeconomic status was independently associated with smoke exposure in the final model ( $\mathrm{B}=0.71 ; 95 \%$ CI 0.34 to 1.07$)$, accounting an additional $7.7 \%$ of the variance. Its effect is independent of overcrowding. The final model, including all exposure variables accounted for $44.3 \%$ of the variance in children's cotinine:creatinine ratios.

\section{DISCUSSION}

The results of this study suggest that only a small proportion of parents report a home smoking ban to protect their children from exposure to environmental tobacco smoke in the home. Many parents use less strict measures, such as those listed in table 2, but this study shows that only a home smoking ban is independently associated with a reduction in smoke exposure among children aged 18-30 months of age after adjustment for the mother's cigarette consumption and other potential confounding variables. Less strict measures appear to have no effect on infant smoke exposure. Mother's average daily cigarette consumption accounted for approximately a third of the effect of strict harm reduction on the children's smoke exposure. These findings are consistent with those we reported from a similarly designed survey among infants aged 2-3 months ${ }^{6}$ which showed an independent effect of a ban on smoking in the house on infant smoke exposure after adjustment for mother's and partner's cigarette consumption, housing tenure and overcrowding. Our results suggest that, despite greater mobility among toddlers and reduced close contact of mother with the child beyond early infancy, not smoking in the house does have a small, independent effect on smoke exposure.

As discussed above, the four RCTs ${ }^{14172123}$ that included interventions designed to encourage home smoking bans did not report significant differences in the use of home smoking bans between intervention and control groups. Until trials are designed, perhaps incorporating the home smoking control index proposed by Sockrider and colleagues, ${ }^{32}$ that are able to directly measure the effects of home smoking bans on children's ETS exposure, we are reliant on observational studies to assess this effect. Four published observational studies $^{6-11}$ report significant reductions in objective measures of ETS exposure associated with home smoking bans but not with restrictions short of a ban. Two studies ${ }^{7}$ report ETS exposure reduction associated with restrictions short of a home smoking ban and one ${ }^{12}$ showed no effect of a home smoking ban.

\section{Limitations and strengths}

Urinary cotinine was only measured on a single occasion. Levels vary considerably in individual children if serial measurements are made. ${ }^{33}$ Individual cotinine levels are dependent on the numbers of smokers in the household, the number of cigarettes smoked, proximity to smokers, the degree of crowding in the home, the size of the rooms, the extent of ventilation, and whether there is ETS exposure in vehicles.

Although we have included household smoking levels and overcrowding in the model, we have no data on size of rooms or extent of ventilation. As with our study of the effect of harm reduction among infants, ${ }^{6}$ the proportion of parents in smoking households reporting no harm reduction strategies was unexpectedly small (6.5\%). The small numbers are likely to have reduced the precision of the mean urinary cotinine: creatinine ratio for this group with the result that a true difference between those using less strict and no strategies may not have been detected. As a result, the finding that less strict measures have little effect on toddler smoke exposure is open to question and needs to be verified in a larger sample.

The strengths of this study are the sampling from a representative population of smoking households with young children in a specific age group, the use of cotinine:creatinine ratio which corrects for urinary dilution, ${ }^{34}$ and the narrow age range of children studied reducing the variation associated with differential speed of metabolism and excretion of nicotine. ${ }^{34}$

Available evidence, including the results of this study, suggest that home smoking bans are likely to be effective in reducing children's ETS exposure although these are unlikely to be sufficient to protect children fully from the adverse effects of passive smoking. As the health effects of passive 
Table 3 Linear regression models fitted on log cotinine:creatinine ratios

\begin{tabular}{|c|c|c|c|c|c|}
\hline Regression models [no. of households] ${ }^{*}$ & $\begin{array}{l}\text { B (regression coefficient) } \\
(95 \% \mathrm{Cl})\end{array}$ & $\begin{array}{l}\text { Beta (standardised } \\
\text { regression } \\
\text { coefficient) }\end{array}$ & I statistic & p value & $\begin{array}{l}\text { Variance }\left(R^{2}\right) \text { explained } \\
\text { by each additional } \\
\text { variable }\end{array}$ \\
\hline $\begin{array}{l}\text { Model } 1 \text { [n= 174] } \\
\text { Home smoking ban (yes } v \text { no) }\end{array}$ & $\begin{array}{l}-0.76(-1.17 \text { to }-0.35) \\
-0.59(-0.94 \text { to }-0.24)\end{array}$ & $\begin{array}{l}-0.27 \\
-0.21\end{array}$ & $\begin{array}{l}-3.62 \\
-3.35\end{array}$ & $\begin{array}{r}<0.001 \\
0.001\end{array}$ & $(0.071) 7.1 \%$ \\
\hline $\begin{array}{l}\text { Model } 2 \text { [ } \mathbf{n}=168 \text { ] } \\
\text { Home smoking ban (yes } v \text { no) } \\
\text { Mother's average daily cigarette consumption }\end{array}$ & $\begin{array}{l}0.61(0.47 \text { to } 0.75) \\
-0.58(-0.93 \text { to }-0.22)\end{array}$ & $\begin{array}{r}0.54 \\
-0.20\end{array}$ & $\begin{array}{r}8.62 \\
-3.23\end{array}$ & $\begin{array}{r}<0.001 \\
0.001\end{array}$ & $(0.287) 28.7 \%$ \\
\hline $\begin{array}{l}\text { Model } 3 \text { [ } n=165 \text { ] } \\
\text { Home smoking ban (yes } v \text { no) } \\
\text { Mother's average daily cigarette consumption } \\
\text { Partner's average daily cigarette consumption }\end{array}$ & $\begin{array}{l}0.62(0.48 \text { to } 0.77) \\
0.15(0.02 \text { to } 0.28) \\
-0.52(-0.86 \text { to }-0.18)\end{array}$ & $\begin{array}{r}0.55 \\
0.14 \\
-0.18\end{array}$ & $\begin{array}{r}8.60 \\
2.23 \\
-3.05\end{array}$ & $\begin{array}{r}<0.001 \\
0.017 \\
0.003\end{array}$ & $(0.008) 0.8 \%$ \\
\hline $\begin{array}{l}\text { Model } 4 \text { [ } n=165 \text { ] } \\
\text { Home smoking ban (yes } v \text { no) } \\
\text { Mother's average daily cigarette consumption } \\
\text { Partner's average daily cigarette consumption } \\
\text { Housing tenure }\end{array}$ & $\begin{array}{l}0.55(0.40 \text { to } 0.69) \\
0.18(0.05 \text { to } 0.30) \\
0.74(0.39 \text { to } 1.09) \\
-0.55(-0.89 \text { to }-0.20)\end{array}$ & $\begin{array}{r}0.48 \\
0.17 \\
0.26 \\
-0.19\end{array}$ & $\begin{array}{r}7.65 \\
2.80 \\
4.19 \\
-3.12\end{array}$ & $\begin{array}{r}<0.001 \\
0.006 \\
<0.001 \\
0.002\end{array}$ & $\begin{array}{l}(0.062) 6.2 \% \\
(0.005) 0.5 \%\end{array}$ \\
\hline $\begin{array}{l}\text { Model } 5 \text { [ } n=159] \\
\text { Home smoking ban (yes } v \text { no) } \\
\text { Mother's average daily cigarette consumption } \\
\text { Partner's average daily cigarette consumption } \\
\text { Housing tenure } \\
\text { Overcrowding }\end{array}$ & $\begin{array}{l}0.57(0.42 \text { to } 0.72) \\
0.17(0.05 \text { to } 0.30) \\
0.71(0.34 \text { to } 1.07) \\
-0.17(-0.53 \text { to } 0.20)\end{array}$ & $\begin{array}{r}0.48 \\
0.16 \\
0.25 \\
-0.06\end{array}$ & $\begin{array}{r}7.60 \\
2.68 \\
-0.95\end{array}$ & $\begin{array}{r}<0.001 \\
0.008 \\
<0.001 \\
0.349\end{array}$ & \\
\hline
\end{tabular}

\section{What is already known on this topic?}

- Limited trial evidence for reduction of ETS in toddlers associated with household smoking ban

- A small number of observational studies indicate that a complete smoking ban reduces ETS but none have studied the effect of a household smoking ban in children 18-30 months old

\section{What this study adds}

- Household smoking ban is associated with a small but significant reduction in toddler ETS measured by urinary cotinine:creatinine ratio

- Measures short of a ban on household smoking are not associated with significant reduction in ETS in this age group

- The effects of a household smoking ban on ETS are independent of levels of adult tobacco consumption, socio-economic status and overcrowding

smoking are likely to be cumulative rather than acute, low levels of exposure may be harmful over time. Renewed efforts are needed to find effective cessation interventions at both the individual and societal levels and to reduce casual passive smoke exposure of children from smokers other than parents and in settings other than the home.

\section{ACKNOWLEDGEMENTS}

We wish to thank the following for their assistance with the study: parents who agreed to take part; health visitors and their managers who enrolled families into the Coventry Cohort Study; and the nurse interviewers who undertook the data collection.

\section{Authors' affiliations}

N Spencer, C Blackburn, C Coe, A Dolan, School of Health and Social Studies, University of Warwick, UK

S Bonas, Department of Medical and Social Care Education, University of Leicester, UK

Funding: The study was supported by a grant from the West Midlands Locally Organised Research Scheme (LORS).

Competing interests: none

\section{REFERENCES}

1 Cook DG, Strachan DP. Health effects of passive smoking: summary of effects of parental smoking on the respiratory health of children and implications for research. Thorax 1999;54:357-66.

2 US Department of Health and Human Services. The health consequences of smoking: a report of the Surgeon General, US Department of Health and Human Services, Centers for Disease Control and Prevention, National Center for Chronic Disease Prevention and Health Promotion, Office of Smoking and Health, 2004

3 World Health Organisation. International consultation on environmental tobacco smoke and child health: consultation report, WHO, Division of NonCommunicable Diseases, Tobacco Free Initiative, Geneva, 1999.

4 leung GM, Ho LM, Lam TH. The economic burden of environmental tobacco smoke in the first year of life. Arch Dis Child 2003;88:767-71.

5 Graham H. When life's a drag. London: HMSO, 1993.

6 Blackburn C, Spencer N, Bonas S, et al. Effect of strategies to reduce exposure of infants to environmental tobacco smoke in the home: cross sectional survey. BMJ 2003;327:257-9.

7 Bakoula CG, Kafritsa YJ, Kavadias GD, et al. Factors modifying exposure to environmental tobacco smoke in children. Cancer Causes Control 1997:8:73-6.

8 Wakefield M, Banham D, Martin J, et al. Restrictions on smoking at home and urinary cotinine levels among children with asthma. Am J Prev Med 2000; 19:188-92.

9 Winklestein ML, Tarzian A, Wood RA. Parental smoking behaviour and passive smoke exposure in children with asthma. Ann Allergy Asthma Immmunol 1997;78:419-23.

10 Matt GE, Quintana PJ, Hovell MF, et al. Households contaminated by environmental tobacco smoke: sources of infant exposure. Tobacco Control 2004; 13:29-37.

11 Johansson A, Hermansson G, Ludvigsson J. How should parents protect their children from environmental tobacco-smoke exposure in the home? Pediatrics 2004; 113:e291-5.

12 Al-Delaimy WK, Crane J, Woodward A. Passive smoking in children: effect of avoidance strategies at home as measured by hair nicotine levels. Arch Environ Health 2001;56:117-22.

13 Roseby R, Waters E, Polnay A, et al. Family and carer smoking control programmes for reducing children's exposure to environmental tobacco 
smoke (Cochrane Review). The Cochrane Library, Issue 3. Chichester: John Wiley \& Sons Ltd, 2004.

14 Wakefield M, Banham D, McCaul K, et al. Effect of feedback regarding urinary cotinine and brief tailored advice on home smoking restrictions among low-income parents of children with asthma: a controlled trial. Prev Med 2002;34:58-65.

15 Chilmonczyk BA, Palomaki GE, Knight GJ, et al. An unsuccessful cotinineassisted intervention strategy to reduce environmental tobacco smoke exposure during infancy. Am J Dis Child 1992;146:357-60.

16 Emmons KM, Hammond K, Fava JL, et al. A randomised trial to reduce passive smoke exposure in low income households with young children. Pediatrics 2001;108:18-24.

17 Erikson W, Sørum K, Bruusgaard D. Effects of information on smoking behaviour in families with preschool children. Acta Pediatr 1996:85:209-12.

18 Greenberg RA, Strecher VJ, Bauman KE, et al. Evaluation of a home-based intervention program to reduce infant passive smoking and lower respiratory illness. J Behav Med 1994;17:273-90.

19 Groner JA, Ahijevych K, Grossman LK, et al. The impact of a brief intervention on maternal smoking behavior. Pediatrics 2000;105:267-71.

20 Hovell MF, Zakarian JM, Matt GE, et al. Effect of counselling mothers on their children's exposure to environmental tobacco smoke: randomised controlled trail. BMJ 2000;321:337-42.

21 Hughes DM, McLoed M, Garner B, et al. Controlled trial of a home and ambulatory program for asthmatic children. Pediatrics 1991;87:54-61.

22 Irvine L, Crombie IK, Clark RA, et al. Advising parents of asthmatic children on passive smoking: randomised controlled trial. BMJ 1999;318:1456-61

23 McIntosh NA, Clark NM, Howatt WF. Reducing tobacco smoke in the environment of the child with asthma. A cotinine-assisted minimal contact intervention. J Asthma 1994:431:453-62.
24 Severson $\mathbf{H H}$, Andrews JA, Lichtenstein E, et al. Reducing maternal smoking and relapse: long-term evaluation of a pediatric intervention. J Asthma 1994;31:453-62

25 Vineis $\mathbf{P}$, Ronco G, Ciccone G, et al. Prevention of exposure of young children to parental tobacco smoke: effectiveness of an educational program. Tumori 1993;79:183-6.

26 Wahlgren DR, Hovell MF, Meltzer SB, et al. Reduction of environmental tobacco smoke exposure in asthmatic children. A 2-year follow-up. Chest 1997; 111:81-8.

27 Wilson SR, Yamada EG, Sudhakar R, et al. A controlled trial of an environmental tobacco smoke reduction intervention in low-income children with asthma. Chest 2001;120:1709-22.

28 Woodward A, Owen N, Grgurinovich N, et al. Trial of an intervention to reduce passive smoking in infancy. Pediatr Pulmonol 1987;3:173-8.

29 Gehrman CA, Hovell MF. Protecting children from environmental tobacco smoke (ETS) exposure: a critical review. Nicotine Tob Res 2003; 5:289-301

30 Spencer NJ, Coe C. Parent-reported health and illness in a whole year birth cohort. Child Care Health Dev 2000;26:489-501.

31 SPSS. SPSS for Windows, version 10.0. Chicago: SPSS Inc, 2000

32 Sockrider MM, Hudmon KS, Addy R, et al. An exploratory study of control of smoking in the home to reduce infant exposure to environmental tobacco smoke. Nicotine Tob Res 2003:5:901-10.

33 Peterson EL, Johnson CC, Ownby DR. Use of urinary cotinine and questionnaires in the evaluation of infant exposure to tobacco smoke in epidemiologic studies. J Clin Epidemiol 1997;50:917-23.

34 Haufroid V, Lison D. Urinary cotinine as a tobacco-smoke exposure index: a mini-review. Int Arch Occup Environ Health 1998;71:162-8.

\section{IMAGES IN PAEDIATRICS}

\section{Silver nitrate burns following umbilical granuloma treatment}

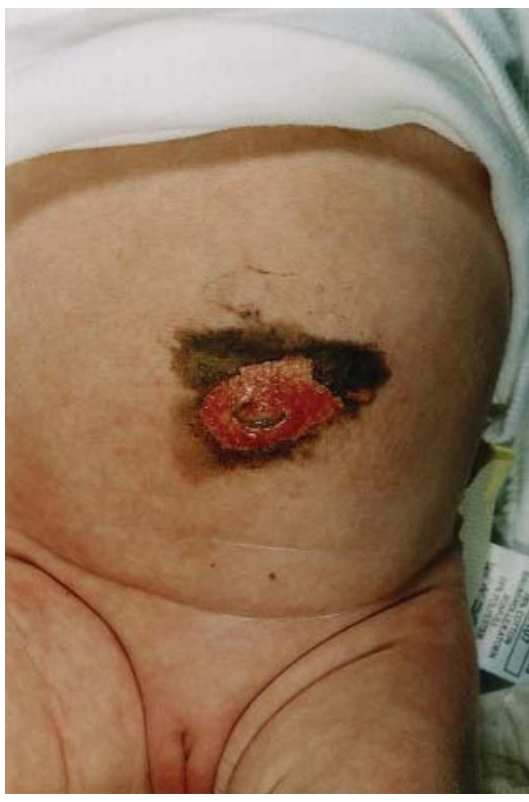

his 30 day old baby girl was admitted to Pinderfields hospital with periumbilical ulceration and pigmentation. Clinically it was felt to be consistent with chemical burns. On further enquiries it was found that she had been treated with silver nitrate for umbilical granuloma by her GP.

There have been case reports documenting burns following silver nitrate application. ${ }^{1}$ Studies by Kesaree et al have shown that salt crystals are very safe and cause 100\% resolution of umbilical granuloma. ${ }^{2}$ Until further studies are done to look for a safe alternative for silver nitrate, it would be wise to use a cautious approach while using silver nitrate. ${ }^{3}$

\section{S Maiiiga \\ P Kumaresan \\ E J Glass \\ Pinderfields General Hospital, Wakefield, UK}

Correspondence to: Dr E J Glass, Department of Paediatrics, The Mid Yorkshire Hospitals NHS Trust, Pinderfields General Hospital, Aberford Road, Wakefield WF1 4DG, UK; ejglass@doctors.org.uk

Consent was obtained for publication of the figure

\section{REFERENCES}

1 Chamberlain JM, Gorman RL, Young GM. Silver nitrate burns following treatment for umbilical granuloma. Pediatr Emerg Care 1992;8:29-30.

2 Kesaree N, Babu PS, Banapurthamath CR, et al. Umbilical granuloma. Indian Pediatr 1983;20:690-2.

3 Daniels J. Is silver nitrate the best agent for management of umbilical granuloma? Arch Dis Child $2001 ; 85: 432$. 